\title{
Política social, protección social y programa empleo temporal: el caso Juárez, México
}

Social protection, Social Policy and Temporary Employment Program: Juarez, Mexico's case

\section{Claudia Marcela Roqueme Ramírez* Myrna Limas Hernández**}

*Nacionalidad: Colombiana.

Grado: Licenciada en Psicología.

Adscripción: Estudiante del programa de Maestría en Ciencias Sociales para el Diseño de Políticas Públicas de la Universidad Autónoma de Ciudad Juárez. Becaria CONACYT.

Área de especialización: Desarrollo Regional.

Correo electrónico: roqueme.marcela@gmail.com

**Nacionalidad: Mexicana.

Grado: Doctorado en Integración y Desarrollo Económico por la Universidad Autónoma de Madrid. Miembro del Sistema Nacional de Investigadores.

Adscripción: Profesora de tiempo completo de la Universidad Autónoma de Ciudad Juárez adscrita al Departamento de Ciencias Sociales.

Área de especialización: Desarrollo humano, pobreza y estudios de género.

Correo electrónico:mlimas@uacj.mx; sritapity@hotmail.com

Fecha de recepción: 11 de septiembre de 2012

Fecha de aceptación: 26 de octubre de 2012 


\title{
Resumen
}

Este trabajo es un análisis del Programa Empleo Temporal (PET) en Ciudad Juárez en el marco del concepto protección social. Para ello se indaga acerca de la política social en México como un intento de comprender hasta qué punto ha contribuido dicho programa a esta alternativa de desarrollo. En este sentido, la revisión bibliográfica se empleó como una herramienta documental y metodológica que permitió conocer otras experiencias en América Latina para situar que la problemática del desempleo y la protección constituyen aún un desafio. Ciudad Juárez no es la excepción. La indagación del PET conduce a proponer que, aunque sus efectos sean positivos temporalmente, los resultados obtenidos son limitados ya que las políticas de acción están encaminadas a solventar en su mayoría contingencias y no una sustentabilidad a mediano y largo plazo. Finalmente, se propone la creación de un índice para monitorear y evaluar el impacto del PET en términos de cobertura, del perfil de los beneficiarios y de los ingresos generados entre los beneficiados.

\section{Palabras Clave: Protección social, politica social, programa empleo temporal, indice}

\begin{abstract}
This paper is an analysis of the Temporary Employment Program (PET) in Ciudad Juarez as part of social protection concept. For this we look into social policy in Mexico in an attempt to understand how the program has contributed to this development alternative. In this sense, the literature review was used as a documentary tool and methodology that allowed us to know other experiences in Latin America to place the problem of unemployment and the protection is still a challenge. Ciudad Juarez is no exception. The investigation of PET leads to propose that, although its effects are temporary positive, the results are limited because action policies are designed to solve the most contingencies and not sustainable in the medium and long term. Finally, we propose the creation of an index for monitoring and evaluating the impact of PET in terms of coverage, the profile of the beneficiaries and the income generated from the beneficiaries.
\end{abstract}

Key words: social protection, social policy, temporary employment program, index 


\section{Introducción}

En la década actual, los temas referentes a crisis económica, crisis financiera, cambio climático, seguridad ciudadana, desempleo, son asuntos que se debaten con gran interés a nivel mundial. En el caso del desempleo, tema donde centra su interés este artículo, preocupa que la tendencia general indique que las plazas laborales demandadas $u$ ofrecidas son cada vez más limitadas y que el número requerido no cubre la demanda anual de trabajo o empleo. ${ }^{1}$ En el caso de la economía mexicana, de acuerdo con Velázquez, ${ }^{2}$ en la década 2000, la demanda de empleo requiere que se generen alrededor de 1,200,000 empleos por año pero se estima que en promedio solo se ofrecen de 500,000 a 600,000 empleos anualmente, lo que representa un déficit acumulado. Si a ello se suma que la tasa de crecimiento económico en la última década en México ha sido menor al $2 \%$ en promedio, no sorprende que en este país se requiera generar alrededor de 8 a 10 millones de nuevos empleos para dar respuesta a un problema estructural. Si ana-

1 Samuelson y Nordhaus (1995) plantean que el trabajo puede entenderse como un factor de producción que refiere al tiempo humano dedicado a producir automóviles por ejemplo por parte de los obreros o a producir personas calificadas en el caso de los docentes. En términos simples, excluyendo a sindicatos y gobierno, en un mercado de trabajo interactúan dos agentes: trabajadores(as) y empresarios(as), los cuales influyen en la determinación de los salarios. En su caso, los trabajadores demandan salarios y ofrecen sus cualificaciones, capacidades y saberes, las empresas ofrecen salarios y demandan trabajadores. Aunque también, desde la interpretación inversa, ocurre que las empresas pueden ofrecer puestos vacantes para las personas desempleadas u ocupadas que demandan algún salario o ingreso digno. Esto es, el estudio del mercado de trabajo permite abordajes dicotómicos: oferta-demanda, trabajador-empresario, trabajosalario. En síntesis, la interpretación derivada de la interacción entre la demanda y la oferta del mercado de trabajo es compleja ya que está sujeta a situar posturas teóricas, metodológicas y políticas que se asocian a problemas y aconteceres que pueden manifestarse a partir de perfilar si el comportamiento económico busca crear empleo o busca explicar el desempleo representado por las dificultades económicas de los individuos y sus familias; esta lectura hace admisible que el trabajo demande y ofrece miles de ocupaciones y tareas considerando distintos niveles de cualificaciones, salarios y perfiles laborales. Por ende, las ciencias sociales consideran uno u otro término.

2 Fuente: Barra de Opinión. Entrevista de Héctor Moctezuma, columnista de Milenio EdoMex a Alberto Velázquez. Video del 16 de agosto de 2010. Ver http://www.youtube.com/watch?v=AoWlHnc8dY0 
lizamos estas circunstancias con detenimiento, sucede que este patrón no es exclusivo de México, se reproduce en territorios de los distintos continentes del mundo afectando a países desarrollados como es el caso de Alemania (Ver nota 1). Esta situación es preocupante, ya que ilustra la falta de capacidad que presentan los países para generar los puestos de trabajo que requiere la población económicamente activa, lo que incentiva el incremento de actividades del sector informal contribuyendo a que la calidad del empleo no solo tienda a reducirse y a que las tasas de desempleo abierto se incrementen, sino que potencia una ola creciente de personas (egresados de programas de educación formal, mujeres, profesionistas, jóvenes, adultos, madres, etcétera) que demanda una fuente de ingresos permanente y segura.

Nota 1. Nuevo aumento de cifra de desempleados en Alemania Berlín, 30 agosto 2012 (PL)

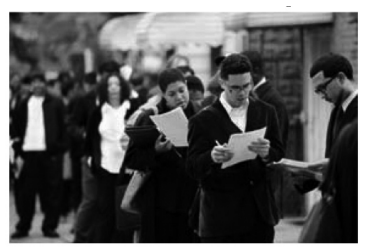

Por quinto mes consecutivo, el número de desempleados subió en agosto en Alemania, sumándose a una serie de datos preocupantes sobre la situación de esa economía, reportó hoy la Oficina Federal de Empleo. El alza fue de 29 mil, para alcanzar los dos millones 905 mil personas desocupadas. Aunque la tasa de cesantía se mantuvo en 6,8 por cieno, los datos evidencian los efectos de la crisis en la llamada locomotora europea. E1 incremento del desempleo disminuye el entusiasmo entre los alemanes y daña el consumo personal, según expertos. Datos divulgados mostraron que el Producto Interno Bruto (PIB) cayó 0,3 por ciento en el segundo semestre del año, en un entorno caracterizado por la disminución de las inversiones ante el temor por la crisis de deuda en la Eurozona. Además algu- 
nos analistas pronostican una reducción en el tercer trimestre y hasta una posible recesión en la segunda mitad de 2012. Por su parte, el Banco Central de Alemania, Bundesbank, reconoció recientemente que la economía de esa nación es golpeada por la baja demanda desde los miembros de la zona. Las perspectivas para las empresas empeoraron en los últimos meses y disminuyeron las contrataciones a causa de la contracción del avance, agregó. $\mathrm{rc} / \mathrm{mfb} .^{3}$

Lo anterior incita a reflexionar bajo cuáles condiciones es posible contar con la capacidad mínima suficiente para resolver el problema del desempleo. Ante esta preocupación, el objetivo de este artículo es revisar cuáles circunstancias caracterizan el mercado laboral en América Latina para luego identificar cuáles esquemas de protección social han intentado resolver la demanda de trabajadores indagando un caso particular: el Programa de Empleo Temporal en Ciudad Juárez, México. Por consiguiente, el artículo parte de conocer qué ocurre en materia de empleo en América Latina y el Caribe. Enseguida se aborda qué es la protección social y cómo se expresan los avances y desafíos enmarcados por los programas de empleo temporal en el caso mexicano, particularizando el caso de Juárez, y finalmente se sugieren algunos apuntes a manera de conclusiones.

\section{El desempleo en América Latina y el Caribe}

Las personas expertas en Economía proponen que la actividad económica se caracteriza por ciclos que refieren a periodos de auge, recesión o desaceleración del crecimiento donde lo esperado es que los aumentos de la demanda, de la inversión, de la productividad y del ingreso tendrán lugar en el mediano plazo posibilitando el ajuste entre la oferta y la demanda de empleo.

Los agentes económicos que tienen la responsabilidad de favorecer este ajuste al operar directamente en este ambiente son tres: gobierno,

3 Fuente: Agencia informativa latinoamericana. Consulta el 30 de agosto de 2012. Ver la referencia al final. 
empresarios y familias. Sin dudarlo, esta tercia de agentes deben buscar los mecanismos adecuados para evitar la caída en los niveles de ingreso, impedir el aumento en las tasas de desempleo abierto y prescindir del incremento de las actividades informales. Sucede que los efectos de las crisis económica y financiera ocurridas en el transcurso de la década 2000-2010 en Estados Unidos y en la Unión Europea parecen expandirse en los países latinoamericanos sin poder anticiparse su fin (Ver nota 2). La ausencia de oportunidades de empleo justifica de alguna manera la oferta de empleos y salarios precarios, pérdida de confianza en las instituciones, vulnerabilidad de las familias a padecer ambientes de pobreza, incrementos en el número de parados, etcétera.

Nota 2. Casi 7 millones de jóvenes están desempleados y unos 27 millones están confinados a la informalidad en América Latina y el Caribe

Viernes, 10 de Agosto de 2012. LIMA. La Oficina Regional de la OIT para América Latina y el Caribe recordó hoy la necesidad de asumir el desafío político de ofrecer oportunidades para casi 7 millones de jóvenes que buscan trabajo sin conseguirlo y para unos 27 millones que están confinados a empleos informales, con salarios precarios y sin protección ni derechos. "La celebración del Día Internacional de la Juventud este 12 de agosto nos debe recordar que es urgente adoptar medidas específicas para estos millones de jóvenes que piden a sus sociedades más y mejores empleos”, dijo la Directora Regional de la OIT, Elizabeth Tinoco [...] pese a los avances en materia de acceso a la educación y a las evidencias sobre una reducción de la pobreza en la región, "el desempleo y los déficit de trabajo decente juvenil impiden aprovechar el potencial de la generación mejor formada y educada que hemos tenido". Tinoco destacó [...] que la falta de oportunidades, la inactividad y la frustración contribuyen a generar cuestionamientos al sistema e incluso comprometen la gobernabilidad [...] Cerca 
de 20 por ciento de jóvenes latinoamericanos no estudian ni trabajan, añadió. "Este es un desafío político", precisó Tinoco. [...]. De acuerdo con los datos más recientes recopilados por la Oficina Regional de la OIT en América Latina y el Caribe la tasa de desempleo urbano de los jóvenes entre 15 y 24 años llega a 14,6\%, más del doble de la tasa general $(6,7 \%)$ y el triple que la tasa de los adultos mayores de 25 años $(5,3 \%)$. En números absolutos se estima que equivale a alrededor de 6,8 millones de jóvenes desempleados, es decir que buscan activamente un empleo pero no lo consiguen. 6 de cada 10 jóvenes que sí encuentran una ocupación sólo logran acceder a empleos informales. En números absolutos son más de 27 millones de jóvenes [...] Cerca de 47 millones de Jóvenes se encuentran trabajando o están buscando activamente empleo. Representan la quinta parte de la población económicamente activa (PEA) urbana total de la región. De ellos, 6,8 millones están desempleados, y 40 millones sí tienen empleo. Alrededor de 59 millones de jóvenes no forman parte de la PEA, ya sea porque están estudiando o porque han desistido de buscar trabajo; Unos 20 millones de jóvenes no estudian ni trabajan (6,9 millones de desempleados y cerca de 13 millones que no estudian ni buscan empleo); más de $60 \%$ tienen empleos informales. 5,1 Millones de jóvenes son emprendedores. 63\% de los jóvenes ocupados, o alrededor de 25 millones, no cuentan con seguro de salud y un porcentaje similar no cotiza a ningún seguro de pensiones. ${ }^{4}$

Esta ligera atención brindada a la relación inversa entre cantidad y nivel de calidad de empleos ofrecidos y demandados sugiere que existe una brecha en tales aspectos que ha llevado a que la periodicidad de las contrataciones sea irregular, temporal e inestable, que los requisitos y perfiles requeridos en las plazas vacantes adviertan esquemas

4 Fuente: Organización Internacional del Trabajo. Consulta el 10 de agosto de 2012. Ver referencia al final. 
de protección muy restringidos y/o que los regímenes de seguridad social tiendan a reducirse ante el descenso paulatino en el número de trabajadores contratados. Los apuntes anteriores se perciben ilógicos en el siglo XXI toda vez que en la época contemporánea sucede que la globalización es un modelo que aparentemente busca facilitar el flujo de bienes, de personas y capitales generando con ello jóvenes y generaciones más formadas, más profesionales y sobre todo capacitadas en el uso de nuevas tecnologías. Sin embargo, los resultados en materia de empleo han resultado contraproducentes toda vez que procede cuestionar - conforme a lo que plantea la nota 2-: ¿Por qué en la década reciente no se ha logrado la cobertura total de demanda de empleo en el mundo? ¿Por qué en todos los países existe una preocupación explícita por la falta de oportunidades y por la calidad de los empleos que se consiguen? Una primera aproximación a posibles respuestas sugiere que en las economías existen diversas fuerzas endógenas y exógenas que impiden equilibrios en las actividades ocasionando perturbaciones en diversos mercados, incluidos los laborales. Las evidencias cotidianas que confirman esta aproximación se expresan a través de los medios impresos, electrónicos o audiovisuales cuando publican el incremento en los números de desempleados, los aumentos en la escasez de empleos, el cierre de una u otra empresa, la reducción en la plantilla de trabajadores, la relocalización de alguna planta o industria ante la búsqueda de lograr la reducción de costos, la caída en el número de registrados en la seguridad social, la disminución en las contrataciones, el ajuste en las jornadas laborales, la desaparición de los horarios extendidos, la declaración en quiebra de empresas, la caída en los niveles de ingresos, el desplome de los salarios de los trabajadores y el patrimonio de las familias, etcétera (ver notas 3 y 4 ).

Nota 3. Clase media de EU retrocede en la última década.

En busca de empleo en EU. Reuters. Los ingresos promedio de una familia cayeron de 72.956 a 69.487 dólares en el 2010. Patrimonio neto de estadounidenses se desplomó y los salarios descendieron. 


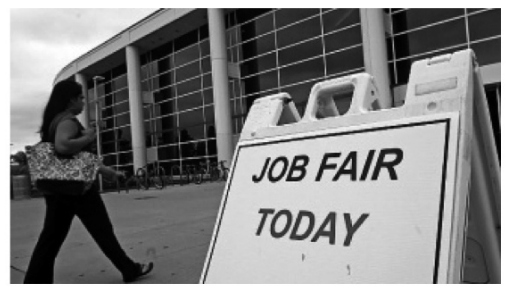

Washington.- La clase media de Estados Unidos se ha contraido drásticamente a lo largo de los últimos 10 años, en los que el patrimonio neto de los estadounidenses se desplomó, los salarios descendieron y los estándares de vida decayeron, de acuerdo a un informe dado a conocer el miércoles. Los asalariados con ingresos medios, considerados durante mucho tiempo como el núcleo sólido del país, son pesimistas y atribuyen directamente el problema a sus legisladores, a los bancos y a las grandes empresas, según muestran los resultados del estudio realizado por el Pew Research Center. "La clase media de Estados Unidos ha padecido su peor década en la historia moderna", escribieron los investigadores. Desde el 2001, los ingresos promedio de una familia cayeron de 72.956 a 69.487 dólares en el 2010, marcó el informe. La mediana de patrimonio neto (valor de los activos menos la deuda) de los hogares cayó desde 129.582 a 93.150 dólares durante el mismo decenio [...]. La apremiante situación de la clase media se ha convertido en un referente de la economía de Estados Unidos tras la reciente Gran Recesión que oficialmente abarcó desde diciembre del 2007 a junio del 2009 [...] la riqueza de los hogares ha disminuido un 35\%, a 66.740 dólares entre el 2005 y el 2010, al tiempo que se desplomaban los valores de las viviendas y los precios de las acciones. Por su parte, el informe de la Fed mostró que el patrimonio neto de una familia media se desplomó a 77,300 dólares en el 2010 desde 126,400 dólares en el 2007. Para su informe, Pew definió a la clase media como hogares con ingresos desde 39,000 a 118,000 dólares, un 
rango que está entre dos terceras partes y el doble de la media

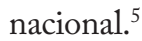

Nota 4. Empleo decente, principal desafío en el mundo: STPS

La titular de la dependencia participó en la VIII Conferencia Iberoamericana de Ministros de Empleo y Seguridad Social, celebrada en Madrid España.

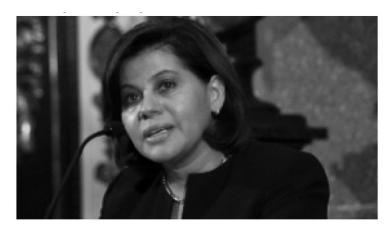

La generación de empleos decentes para todos es uno de los desafíos globales más urgentes, en particular para integrar a los jóvenes y otros grupos vulnerables al mercado laboral, aseguró la titular de la Secretaría del Trabajo y Previsión Social (STPS), Rosalinda Vélez Juárez [...] en la VIII Conferencia Iberoamericana de Ministros de Empleo y Seguridad Social, celebrada en Madrid España. Destacó que el empleo debe estar en el centro de las políticas macroeconómicas para seguir avanzando hacia el objetivo de un crecimiento fuerte, sostenido y equilibrado en el mundo. [...] señaló, que sólo con la acción coordinada y decidida de gobiernos, trabajadores y empleadores, será posible regresar al camino del desarrollo incluyente, que genere empleos de calidad, contribuya a erradicar la pobreza y logre el bienestar de las personas. [...] Para alcanzar este objetivo, recordó, son necesarias las reformas estructurales para mejorar la competitividad y facilitar el acceso al mercado laboral formal, con pleno respeto a los derechos de los trabajadores. "Las reformas estructurales deben combinarse con políticas activas del mercado laboral, que faciliten la vinculación

5 Fuente: El Financiero. Consulta 23 de julio de 2012. Ver referencia al final. 
entre las empresas y los buscadores de empleo, y así éstos puedan insertarse en empleos de calidad", sintetizó. [...] el reto para todos los países es que la estabilidad y la recuperación económica tengan un rostro humano, es decir, que nuestras poblaciones cuenten con oportunidades de desarrollo pleno, a través del empleo de calidad. ${ }^{6}$

Los hechos actuales sugieren que el dominio del escenario pesimista en el ambiente laboral seguirá imperando. Con base en las notas no sorprende que un número creciente de personas tiende a no conseguir un puesto de trabajo por razones involuntarias; efectivamente, la situación de paro o desempleo forzoso no solo se ha convertido en un problema global, sino que ha generado efectos colaterales que se expresan a través de desajustes o desequilibrios en la oferta y demanda laboral por dos razones: i) experimentar una reducción en los niveles de productividad ante el ritmo de crecimiento de las tecnologías supeditada a ritmos de crecimiento débiles, no sostenidos y desequilibrados, y ii) hacer frente a la caída en los niveles de ingresos y de bienestar de los individuos y de sus familias. La suma de estas condiciones adversas ha llevado a que las familias hagan frente a círculos viciosos de carencias y ambientes críticos de deterioro social que a la vez que retroalimentan y fortalecen un modelo reproductor de pobreza con privaciones y niveles de degradación en la calidad de vida generan que amplios grupos de población - particularmente jóvenes - sean marginados al enfrentar con dificultad la satisfacción de necesidades esenciales (ingreso, alimentación, educación, salud, vivienda, vestido, transporte y ocio). Por consiguiente, dado que la prioridad del mercado laboral exige medidas inmediatas, enérgicas y contundentes para abatir el desempleo adquiere sentido revisar cuáles alternativas se disponen en materia de políticas de protección social. Para este abordaje resolvamos qué es la política social (PS) y qué significa la protección social (ps).

6 Fuente: El Financiero. Consulta el 23 de agosto de 2012. Ver cita al final. 


\section{Política socialy protección social: origenes y generalidades}

Los antecedentes históricos que enmarcan los abordajes de política social y protección social se asocian con el concepto Estado de Bienestar, que fue formulado como una alternativa para estabilizar las economías ante los fallos del mercado. Según la propuesta original, este modelo - cuyos referentes principales vía formato Estado de Bienestar se sitúan en Alemania y Gran Bretaña a finales del siglo XIX — buscó promover un sistema de seguridad dirigido a trabajadores industriales, así como reformas laborales para tratar los temas de pensiones y seguridad ante la enfermedad, invalidez y desempleo.

Una revisión somera de este formato revela que la presencia de cambios estructurales e incrementos en las desigualdades sociales sumados a la aparición de movimientos sociales, cuyas demandas consistían en exigir mejores niveles de ingresos y de calidad de vida dieron paso a enunciar la política social como un recurso teórico y con posibilidad de admitir la intervención estatal para potenciar la provisión de asistencia social en beneficio de los trabajadores. Este posicionamiento advirtió que al centrar la atención en la política social era conveniente reconocer que resultaba difícil asignarle una definición única por lo que, trasladándonos a un tiempo reciente, Montoro (1997) sugiere que fue pertinente resaltar 4 asuntos importantes en su tratamiento; que proponen: 1) el origen de la expresión sozialpolitik se ubica en 1845 y se identifica a Robert Mohl como el "padre" de la misma; 2) la idea de política social parece estar íntimamente relacionada con la figura del Estado benefactor, Estado protector o Estado de bienestar y esta denominación se debe a la actuación del Estado como agente recaudador y redistribuidor de bienes en el tiempo posterior a la Segunda Guerra Mundial; 3) Titmuss, Donati y Habermas son tres autores clave que constituyen las referencias indicadas al estudiar el tema política social.

7 Para conocer los antecedentes de la política social en el mundo y sus primeras definiciones se recomienda revisar el capítulo 2 "Fundamentos Teóricos de la Política Social” de Ricardo Montoro (1997) cuya descarga gratuita puede realizarse desde el sitio http:// www.uam.es/personal_pdi/economicas/rmontoro/Mis\%20articulos/politicasocial.pdf 
Y 4) la política social puede expresarse a través de tres tipos posibles conforme a Donati (1985, citado en Montoro op.cit) modelizados bajo distintas formas: TIPO I: como caridad; como garantía del control social, como mecanismo de reproducción social, como realización del derecho social de ciudadanía; TIPO II: como modelo residual, como modelo adquisitivo-ejecutivo, como modelo institucional-redistributivo; como modelo total; y TIPO III: como modelo formalista, como modelo normativo y como modelo materialista. En definitiva, parafraseando a Montoro, independientemente de los modelos que adapte la política social, la tendencia de la intervención del Estado debe redefinirse considerando la participación de la iniciativa privada para identificar el conjunto de necesidades personales y colectivas que habrán de resolverse de manera equilibrada, racional sin poner en peligro el orden y la estabilidad social.

$\mathrm{Al}$ respecto, una definición integradora de política social sugerida por Montoro (idem) indica que refiere al diseño y la ejecución programada y estructura de todas aquellas iniciativas adoptadas para atender una serie de necesidades consideradas básicas para la población [...] donde figuran la salud, la educación, el trabajo, una jubilación digna, el derecho al trabajo, $y$, en general, el mantenimiento de unas condiciones generales que impidan la marginación social en cualquiera de sus formas. Sin embargo, matiza, las necesidades se adecuan a tiempos, espacios y poblaciones. ${ }^{8}$ Esta aproximación pone al descubierto que las definiciones de la PS pueden ser tan amplias como las necesidades no previstas en el futuro, por lo que tiene sentido apuntar un par de acepciones más que nos induzcan no solo a su comprensión sino a revisar un caso empírico previamente anticipado: el PET. Revisemos las dos posturas de la definición. Ortiz

8 De este modo el listado de necesidades de la población del siglo XXI no necesariamente coincide con aquellas identificadas en la era previa a la caída del muro de Berlín. Por ejemplo, entre las cuestiones que precisan una atención prioritaria en la época actual se cuentan: la protección del medio ambiente, la salvaguarda de la igualdad y equidad de género, la protección a las personas de la tercera edad, la defensa de la diversidad de géneros y estructuras familiares, anticipar las nuevas enfermedades provocadas por el uso de nuevas tecnologías, combatir la pobreza y la exclusión social, adecuar las leyes laborales a la década y condiciones actuales; etcétera. 
(2007) señala que la política social a menudo refiere a un enfoque dirigido a eliminar las desventajas sociales, los riesgos y las vulnerabilidades que puedan tener diversos sectores de la población a partir de no ser beneficiarias o usuarios de servicios básicos como educación, salud, seguridad social, por lo que requieren esquemas de protección y de justicia social. Ceja (2004) postula que la política social es la forma como el Estado busca construir una sociedad cohesionada y equitativa por medio de estrategias y políticas concretas, cuyo fin principal es facilitar la convergencia entre los intereses individuales y los intereses comunes. Pero eso no es todo, al analizar la instrumentación de la política social en México en programas de pobreza por ejemplo, esta autora precisa que le son inherentes tres rasgos: su carácter universal, su focalización y la integridad o buena integración de instrumentos.

Por ende, al asociar la PS con la protección social cabe concebir que sus objetivos varían no solo en función de los requerimientos de la población, sino conforme a los contextos históricos y espaciales. ${ }^{9}$ Así resulta que al revisar qué ha ocurrido en Latinoamérica y en México respecto al ejercicio de la política social se aprecia —atendiendo las formulaciones de Sottoli (2002: 43) — que la política social debe entenderse como "política"10 y su enfoque (tradicional, nuevo o emergente) debe re-adaptarse en función de objetivos, cobertura/alcance, destinatarios, actores, institucionalidad, dimensión política, financiamiento, prioridades, relación política social-política económica y conforme al ideario social para destacar su alcance regional. Un acercamiento al caso de América Latina propone que la PS ha asumido un lugar "tradicional" toda vez que reviste un carácter asistencial, que si bien ha permitido aliviar los problemas o necesidades en el corto plazo, ha prolongado la dependencia de las personas de los apoyos del gobierno sin posibilitar que amplios colectivos superen las situaciones

9 Para mayores detalles revisar el texto "La política social mexicana de cara a la pobreza" cuya descarga gratuita está disponible en el sitio http://www.ub.edu/geocrit/sn/sn-176. $\mathrm{htm}$. Además ver referencia bibliográfica en este artículo.

10 "Es decir, como objeto y resultado de procesos de decisión política que ocurren dentro de las condiciones de un determinado modelo de relaciones entre el Estado, la economía y la sociedad [...]". (Sottoli, 2002: 44). 
de vulnerabilidad que les son comunes. De esta forma, los efectos de dichas medidas ha exigido la disolución de formas tradicionales para dar cabida a formas emergentes de política social integral y sostenida que apunten a diluir el "estado-centrismo" y favorecer el "mercadocentrismo" de modo que la descentralización de funciones del Estado otorgue una mayor participación al sector privado.

¿Cuál es el balance en América Latina en materia de política social? A partir de la década 1980 se puso al descubierto la necesidad de introducir medidas de compensación social, tales como programas de empleo de emergencia, subsidios alimenticios y fondos de emergencia social para atenuar los efectos de los programas de ajuste estructural. Pero ¿qué ocurrió? Las economías latinoamericanas, incluida la mexicana, no lograron ni han logrado conseguir niveles mínimos y suficientes de crecimiento económico, lo que se ha traducido en diversos déficit o rezagos sociales acumulados que se han expresado a través de aumentos en las tasas de desempleo abierto, aumento del empleo informal, descensos en los niveles de productividad, incrementos en los índices de pobreza, incrementos en la brecha de los niveles de ingreso, etcétera (ibíd: 46).

En el caso de México, la política social se ha concentrado a nivel federal en la Secretaría de Desarrollo Social (SEDESOL). Esta instancia del gobierno coordina, ejecuta y evalúa las políticas y programas sociales con el objetivo de fortalecer las instituciones, mejorar la calidad de los servicios y ampliar la cobertura. No sorprende que esta dependencia establezca como misión "la realización de acciones que contribuyan a la igualdad de oportunidades para todos los ciudadanos" por lo que el diseño de políticas públicas habrán de responder a los complejos y multidimensionales problemas (pobreza, vulnerabilidad y contingencias como el desempleo) que impidan el adecuado desarrollo de las capacidades de la población. ${ }^{11}$ Vale apuntar que dicha política ha estado en concordancia con el modelo latinoamericano, dado que se ha caracterizado por responder a la estrategia económica que propugnaba - incluso hasta finales de los años ochenta- en las políticas

11 Síntesis realizada del Plan Nacional de Desarrollo 2007-2012. 
de crecimiento que el modelo adoptado crearía las bases del bienestar. De esta manera se confirma que durante las décadas de los ochenta y noventa, con base en los planteamientos de Ortiz (2007), la PS en México estuvo centrada en proporcionar asistencia social y servicios básicos a la población, pero bajo medidas incipientes, insuficientes y residuales (esto es bajo un enfoque de importancia secundaria) bajo una lógica "estado-centrista" que no lograron conseguir un desarrollo social y económico equilibrado. Empero ante este balance surge a comienzos del siglo XXI un consenso considerando la postura "mercadocentrista", en el que se plantea que la política social debe partir de las funciones primarias del Estado, suponiendo más allá que un conjunto limitado de redes de asistencia y servicios para cubrir los fallos del mercado que da cabida a constituir el logro del crecimiento económico y la equidad social como una parte crucial de toda Estrategia Nacional de Desarrollo.

En conclusión, puede entenderse que el marco de la protección social está estrechamente relacionado con la política social en tanto que la primera puede considerarse como el conjunto de instrumentos utilizados por el Estado para promover y mejorar el bienestar de las personas al posibilitarles herramientas para afrontar situaciones de riesgo en un momento determinado, y la segunda orienta o marca las directrices que preserven el bienestar social procurando el incremento de beneficios. De igual manera, coincidiendo con diversos organismos internacionales como la Organización Internacional del Trabajo (1999), el Banco Interamericano de Desarrollo (2000) y la Comisión Económica para América y el Caribe (2011), se advierte que la protección social constituye un mecanismo que trata de minimizar los efectos negativos generados por la estructura económica, política y social desde la postura capitalista que, pese a conseguir avances, pone al margen de los beneficios a una cantidad o parcela importante de la población.

Dado lo anterior, es claro que protección social, previsión social y seguridad social son términos sujetos a confusión o a considerarse sinónimos. Empero, cabe aceptar que en esa tercia reviste una diferencia. En palabras de Morales (2006) la diferencia entre la protección 
social, previsión social y seguridad social consiste en que la protección social puede asumirse como una categoría independiente, más global y amplia, que comprende las subcategorías de previsión y seguridad. De esta manera, la protección social es un instrumento útil para la promoción del bienestar humano que favorece la integración y la equidad tanto de hombres y mujeres en condición de vulnerabilidad, e incluye variables de orden económico, político y social que garantizan que las personas puedan enfrentar eventos adversos como el desempleo.

En este sentido, muchos de los temas que se debaten en este terreno tienen que ver precisamente con lo laboral, ya que como elemento sobresaliente de la vida provee un ingreso que se traduce en seguridad. Por ello, no debe sorprender que un objetivo primordial de los gobiernos es dar protección a las personas que carecen de ella o que están muy poco amparadas, con lo que busca garantizarse otorgar un ingreso mínimo que coadyuve a contrarrestar situaciones de vulnerabilidad, como lo es la falta de empleo. En estas circunstancias, la protección social representa un desafío en la creación de medidas que transciendan el carácter asistencialista y genere ciertas condiciones de bienestar. Por tanto, para no ahondar en este debate, centremos la atención en la protección social considerando un programa en particular: el esquema del empleo temporal.

\section{Antecedentes del Programa Empleo Temporal en América Latina}

La revisión de diversos informes emitidos por la Comisión Económica para América Latina (CEPAL) y publicados de manera electrónica respecto a experiencias de protección social sugieren que por lo común esta ha estado basada en los mecanismos clásicos como los seguros, cuyos resultados han amparado parcialmente a la población trabajadora, implicando que la asistencia social no haya cubierto a la mayoría de las personas. En el caso de México, el sistema de protección históricamente ha tenido una estructura fragmentada, costosa y de poca cobertura, reflejando con ello la desigualdad de la distribución del ingreso. El resultado general de este escenario es que una gran proporción de 
la población y en especial quienes trabajan en el sector informal, aún tienen poca o ninguna protección social contra los riesgos como el desempleo. Dado este contexto y las dificultades enfrentadas, se ha optado por promover programas de empleo temporal para intentar proveer acciones de protección social en función de brindar seguridad en los ingresos por baja demanda laboral, así como instrumentar una serie de mecanismos que permitan la reincorporación de las personas, aunque de manera temporal, al mercado de trabajo.

Es importante señalar que en México no existe un seguro de desempleo en sentido estricto, pero sí una indemnización por finalización del trabajo establecida en la Ley Federal del Trabajo la cual recae sobre el empleador. En América Latina tan solo seis países cuentan con seguro de desempleo: Argentina, Brasil, Chile, Uruguay, Venezuela, Ecuador. Uruguay es el país más antiguo en cuanto a seguro de desempleo, su propuesta data de 1934; en cambio, Chile es el país con menos tradición en la materia, ya que introdujo esta alternativa en 2001. La lectura de esta experiencia, conforme a lo señalado por la Organización Internacional del Trabajo (OIT), indica que los seguros de desempleo en América Latina son muy restrictivos y excluyen a los trabajadores asalariados más vulnerables como es el caso de los trabajadores de la construcción, domésticos, agrícolas y jóvenes. En términos generales, los porcentajes de indemnización compensatoria oscilan entre 40 y $80 \%$ de los salarios y se espera que cuando se entrega una indemnización final se "ayude" al trabajador durante el tiempo que dura el desempleo. La problemática identificada respecto a los seguros de desempleo en América Latina considera la ausencia de relación entre tales seguros y las políticas de mercado de trabajo como son la capacitación y los servicios de empleo. En América Latina, este tipo de programas tiene una larga historia en la que aparecen como intervenciones destinadas a potenciar el capital humano, cuyo propósito es ofrecer oportunidades productivas; nacen como una respuesta a los vaivenes del ciclo económico y a las crisis que se caracterizan por el aumento del desempleo estructural y la persistencia de la pobreza convirtiéndolos en componentes permanentes de la política social. Así, se tiene por ejemplo que el director general de la OIT, Juan Somavia, ha 
declarado que desde la Oficina regional de la OIT se han orientado políticas nacionales para incentivar el empleo juvenil como son:

Hacer de la generación de empleo juvenil una prioridad en la agenda; incluir el tema de los jóvenes en el diálogo social entre los actores fundamentales de la economía, apoyar el espíritu emprendedor de los jóvenes para que pongan en práctica sus propias iniciativas a través de sistemas de microcrédito como "incubadoras de empresas", dar eficiencia y cobertura a los servicios de empleo, sitios digitalizados, oficinas donde se de a los jóvenes información en tiempo real sobre posibilidades inmediatas, ofrecer la educación y formación necesarias para una mejor articulación con el mercado laboral, dar acceso a los jóvenes a un sistema de créditos educativos, transferencias monetarias condicionadas y becas sueldo para que puedan continuar su formación y recalificación laboral, entre otras. (OIT, 2012)

Y en su mensaje por el Día Internacional de la Juventud, aclaró: "traducir estas orientaciones en respuestas efectivas exigirá desplegar una firme voluntad política, hacer gala de creatividad y asignar los recursos necesarios. Será necesario forjar alianzas de colaboración a escala local y nacional, con el apoyo de la acción internacional". ${ }^{12}$

Los apuntes previos hacen reflexionar, en concordancia con Santibáñez (2007), que los programas de emergencia vinculados al empleo temporal han sido mecanismos relativamente eficaces para responder a situaciones de crisis, puesto que han aportado ingresos a los grupos de la población más vulnerables. No obstante, la limitación de los programas de empleo que operan bajo esta modalidad es que generan beneficios en el corto plazo y, por tanto, son efectivos en situaciones de baja demanda laboral; asimismo, otro riesgo que se advierte es que la focalización de la población objetivo debe ser correcta y los sistemas de información deben ser adecuados de modo que permitan seleccionar apropiadamente a los beneficiarios. De lo contrario, ocurrirá lo

12 Fuente: OIT, Nota Casi 7 millones de jóvenes están desempleados y unos 27 millones están confinados a la informalidad en América Latina y el Caribe. Consulta el 10 de agosto de 2012. Ver referencia al final. 
que apunta Salcedo (2004) en el caso de Mendoza, Argentina. Los programas temporales han generado que se incremente el espacio de los empleos no plenos con corta duración, implicando que las prestaciones ofrecidas estén por debajo del salario mínimo, conllevando a los grupos "beneficiarios" a entornos de exclusión sujetos a la insatisfacción de las necesidades básicas.

Frente a lo anterior, pese a las limitaciones, imperfecciones y precariedades intrínsecas en los programas de empleo temporal vale reconocer que encierran cierto propósito y valor, ya que de lo contrario los descalificaríamos difundiendo su no aporte significativo en la protección social de la población objetivo. Efectivamente, su aporte no es significativo, pero en definitiva, puede considerarse que dan respuesta a un problema grave de ocupación, que de no implementarse el número de personas con carencias y vulnerabilidad social, sería similar a una burbuja gigantesca a punto de explotar. Así sucede, trasladándonos al plano local, que adquiere sentido revisar cómo puede interpretarse el concepto de protección social en una experiencia mexicana en concreto, como es el caso del programa de empleo temporal (PET) en Ciudad Juárez, para explorar hasta qué punto ha contribuido al propósito de combatir específicamente algunos problemas de índole socioeconómico causados por el desempleo y por algunos otros factores de vulnerabilidad económica. Es justo este abordaje el que se expone a continuación.

\section{Programa Empleo Temporal en Ciudad Juárez: un esfuerzo de política y protección social}

Saavedra (1968) propone que la política social es un conjunto de medidas que tienen la finalidad de elevar el nivel de vida de la población a partir de la distribución equitativa de los beneficios sociales. Salazar y Valdrini (1988) la identifican como el conjunto de acciones que se relacionan con el bienestar de los individuos y de los grupos en concordancia con una normatividad. Por su parte, Ortiz (2007) sugiere que la política social se define a menudo en términos de la oferta de servicios en educación, salud y seguridad social bajo el propósito 
de aliviar problemas en el corto plazo, cuyos beneficiarios principales concentren a personas en situaciones de vulnerabilidad. En cambio, la protección social refiere al conjunto de instrumentos utilizados por el Estado para promover y mejorar el bienestar de las personas en función de activar mecanismos que permitan superar situaciones de contingencia. Ese es el caso del programa empleo temporal (PET). El PET operado en México es un programa estratégico del gobierno federal pensado, desarrollado e implementado en conjunto con otras instancias gubernamentales del nivel estatal y municipal —además de varias organizaciones de la sociedad civil- para desarrollar una estrategia integral que pudiera contrarrestar particularmente la problemática multifactorial que enfrenta la sociedad, incluida la juarense. Ya que referimos a esta población, vale ilustrar algunas generalidades.

Juárez es un municipio fronterizo localizado al norte de la república mexicana que colinda con el sur de los Estados Unidos a través de condados del estado de Texas y de Nuevo México. Según el XIII Censo de Población y Vivienda realizado por el Instituto Nacional de Estadística y Geografía (INEGI) en México, esta localidad registra una población que supera el millón de habitantes. De esta cifra (1332,131 personas) el $49.97 \%$ son del sexo masculino y el resto, $50.03 \%$, corresponde al sexo femenino (665,691 y 666,440 habitantes respectivamente). Según Barraza (2009), la principal actividad económica desplegada en esta población se ha basado desde finales de la década 1960 y principios de 1970 en la industria maquiladora dentro del sector manufacturero. Esta industria, al igual que la ciudad, en el transcurso del siglo XXI se ha visto afectada no solo por las crisis económicas originadas en Estados Unidos y Europa, sino por el clima de inseguridad y violencia que recientemente ha azotado a la ciudad trastocando la seguridad económica de los residentes juarenses. La expresión de ese clima se ha representado a través de diversos fenómenos delictivos que propiciaron la huida de la inversión extranjera en la ciudad ocasionando un incremento exorbitante en la tasa de desempleo, así como grandes niveles de insatisfacción e incertidumbre laboral (ver nota 3). Como prueba, las cifras del Instituto Mexicano del Seguro 
Social muestran la pérdida de más de 91 mil empleos en el periodo Octubre 2007-Mayo 2009 (Ver nota 4).

Nota 3. Incesante, el desempleo en Juárez.

El número de despidos este año es menor al de 2001, afirman representantes de las plantas maquiladoras y la Cámara Nacional de la Industria de Transformación Jueves 02 de mayo de 2002. Luis Carlos Cano C./Corresponsal | El Universal.

Ciudad Juárez, Chih. Este primero de mayo, los trabajadores juarenses tuvieron poco que conmemorar; a diferencia de hace dos años, cuando la oferta de trabajo era abundante, ahora la situación es diferente por el desempleo campeante, principalmente en la industria maquiladora, la más afectada por la recesión económica en Estados Unidos. Aunque representantes de la industria maquiladora y de la Cámara de la Industria de Transformación en esta frontera reportan menos desempleo que el registrado el año pasado, y hasta algunas empresas que ya han recontratado personal, aún no se recuperan los más de 45 mil plazas perdidas durante el 2001 y parte de este año. Actualmente en las 316 maquiladoras hay 250 mil empleados.

Testimonios

Dos trabajadores afectados por los problemas económicos de las maquiladoras son Arturo Ramírez y Raymundo Núñez. Ambos laboraron en distintas áreas y plantas maquiladoras, pero a los dos los afectaron los recortes de personal del último año; ahora, la falta de empleo los mantiene en busca de una oportunidad [...] Arturo Ramírez, de 32 años de edad, dice que desde que salió de la maquiladora, hace casi un año, no ha logrado colocarse de nuevo en alguna empresa de ese sector. "En la maquila donde estaba hacen motores para aparatos 
eléctricos y a veces ganaba más de los 600 pesos por semana con los bonos que nos daban, pero luego vinieron los recortes y a buscarle por otro lado, y eso es lo que hago desde entonces", comenta [...] Raymundo Núñez comenta "Cuando estaba en la maquila no batallaba mucho, porque podía sacar todos los bonos que nos daban, como el de asistencia, el de puntualidad y aparte comía en la misma fábrica, pero ahora no todos los días tengo chamba y me la veo más difícil para llevar el chivo a la casa" [...] Como Arturo y Raymundo, muchos trabajadores más están a la espera de ser recontratados en las maquiladoras. $^{13}$

Nota 4. Desempleo en Ciudad Juárez Fri, 09/02/2011 - 5:35pm

El fantasma del desempleo azota a Ciudad Juárez. Los despidos se multiplican rápidamente y como es de suponerse, la mayoría de ellos son injustificados. Tan sólo de mayo a julio se han perdido cerca de cuatro mil empleos, es decir aproximadamente 1,300 cada mes. Esta ciudad que hace apenas unas cuantas décadas fuera la de menor índice de desempleo del país, ahora está pasando por uno de sus peores momentos [...] Esto está ocasionando que un gran número de personas queden en la vil pobreza. Por otro lado, las empresas que aún operan en la ciudad, están recortando tanto su plantilla laboral como sus prestaciones, de tal forma que si antes en una familia había hasta 3 ó 4 miembros laborando, ahora con suerte trabaja uno y para colmo con una percepción económica más reducida [...] En los parques industriales se pueden ver en algunas maquiladoras anuncios de vacantes, y aun cuando sólo tienen unos 20 lugares disponibles, afuera se pueden ver filas de hasta 100 personas esperando con la ilusión de tener una entrevista de contratación. A esos lugares acuden desde las 4:00 o 5:00 de

13 Fuente: El Universal. Consulta el 19 de julio de 2012. Ver referencia al final. 
la mañana mujeres y hombres, cuyas edades fluctúan entre los 17 a los 40 años o más, aunque sabiendo que la edad promedio de contratación es sólo de los 18 a 35 años [...] Cifras del Instituto Mexicano del Seguro Social, muestran que en Ciudad Juárez se perdieron más de 91 mil empleos de octubre del 2007 a mayo del 2009, y pese a que desde entonces a la fecha se han creado poco más de 26 mil, faltarían de recuperarse un poco más de 65 mil. Debido a esto muchas personas se han registrado en los programas ayuda a la pobreza que promueven las instituciones de gobierno. Tan sólo el año pasado el padrón de "Oportunidades", programa federal destinado a la población en extrema pobreza, se incrementó de 12 mil familias a 26 mil en la ciudad. ${ }^{14}$

Tal como apuntan los registros hemerográficos, históricamente la maquiladora ha sido la fuente de empleo más demandada por los residentes de Juárez, no solo por las prestaciones laborales otorgadas (bonos de asistencia, puntualidad, alimentación, transporte, pago de horas extras, servicio médico, etcétera), sino por las oportunidades de ascenso que se procuraban. Pero, como se ha dicho, tales ventajas se vinieron abajo por las diversas situaciones adversas que han azotado la ciudad. Y no solo en el plano económico, en el ámbito político la situación no es distinta, ya que se han dado a conocer ciertos nexos de algunos funcionarios públicos con el crimen organizado afectando la legitimidad y credibilidad del gobierno municipal como actor político capaz de dar solución integral a la problemática en cuestión. A este contexto adverso, incluida la pobreza, vulnerabilidad y desolación, se ha sumado el padecimiento de una crisis social que ha costado un número histórico de muertes (defunciones con crecimiento exponencial inesperado) que han tenido lugar no solo en la localidad sino a nivel nacional. La coyuntura actual es apremiante y ha exigido mayores esfuerzos por parte de los gobiernos municipal, estatal y federal, así

14 Fuente: Mexico Solidarity Network. Consulta el 19 de agosto de 2012. Ver referencia al final. 
como de la sociedad civil juarense. Justamente el concierto de intereses ha llevado a sugerir que una salida alternativa y benéfica que evada este laberinto de desempleo, crimen e inseguridad pública ha consistido en operar la estrategia Todos somos Juárez. En síntesis, dicha estrategia comprende una serie de acuerdos para la ejecución de programas y políticas públicas, cuyo objetivo es precisamente resolver problemas de cada una de las dimensiones de la vida social de los juarenses, suscitados por la violencia y la inseguridad, atendiendo los ámbitos de la seguridad pública, la economía, el trabajo, la salud, la educación y otros aspectos importantes del desarrollo social. Un programa clave que se enmarcó dentro de esta estrategia fue el PET.

Como antecedente se tiene que el PET inició sus operaciones en el año 1995 a cargo de la Secretaría de Desarrollo Social (SEDESOL) y la Secretaría de Comunicaciones y Transportes (SCT). A partir del 2009, este programa se incorporó a la Secretaría del Trabajo y Previsión Social (STPS) a través de la Coordinación General del Servicio Nacional de Empleo (SNE) y la Secretaría de Medio Ambiente y Recursos Naturales (SERMARNAT). En la actualidad, 2012, el PET descansa en las actividades desempeñadas desde la SEDESOL bajo la sentencia "Vivir Mejor" y cuenta con varias sedes en las diversas entidades federativas. Dentro de las reglas de operación del año 2011, el PET se fundamenta en los ejes tres y cuatro del Plan de Desarrollo 2007-2012 que corresponden al inciso de Igualdad de Oportunidades y Sustentabilidad Ambiental. ${ }^{15}$ Para el primer caso, se argumenta que una política social que tienda solo a resolver las necesidades no es efectiva ni viable, por lo que se pretende dar oportunidades de manera equitativa a los ciudadanos a fin de resolver las causas profundas de la pobreza; se establece que para ello se otorgará atención prioritaria a grupos en situación de vulnerabilidad a partir de políticas focalizadas particularmente en materia del trabajo temporal. En lo que respecta al eje cuatro, se plantea impulsar el manejo sustentable de los recur-

15 Fuente: Presidencia de la República. Sitio http://presidencia.gob.mx/. Consulta el 09 de agosto de 2012. 
sos naturales a través de proyectos productivos rurales. ${ }^{16}$ En cuanto a los objetivos del Programa Empleo Temporal, el plan contempla como objetivo general "Contribuir a la protección social de la población afectada por baja demanda de mano de obra o una emergencia” y como objetivo específico "Proporcionar a hombres y mujeres de 16 años de edad o más apoyos temporales en su ingreso para afrontar los efectos de una baja demanda de mano obra o de una emergencia, como contraprestación por su participación al ejecutar proyectos que contribuyan al mejoramiento de las condiciones familiares o comunitarias". La programación contempla de uno a seis meses como el tiempo máximo de duración del empleo; la otorgación de un apoyo económico, consistente en jornales equivalentes al 99\% de un salario mínimo general diario vigente en la zona económica en que se desarrolla el proyecto, que podrá entregarse a través de medios electrónicos o en efectivo hasta por un máximo de 3 jornales diarios, y los rubros de atención o apoyo que considera son: mejoramiento de la salud, preservación del patrimonio histórico, mejoramiento de infraestructura local, conservación y reconstrucción de la red rural y alimentaria, conservación ambiental, comunicación educativa ciudadana, y apoyo a jóvenes para la educación y el empleo (ver fotografía 1). En específico, la SEDESOL aclara que este programa proporciona ocupaciones a corto plazo a trabajadores semi-calificados o no calificados en proyectos basados en el uso intensivo de mano de obra relacionados con la creación y reparación de obras de infraestructura económica, social y comunitaria (ver tabla 1$)$.

16 Fuente: Secretaría de Desarrollo Social. Sitio http://www.sedesol.gob.mx/es/SEDESOL/Empleo_Temporal_PET. Consulta el 11 de agosto de 2012. 


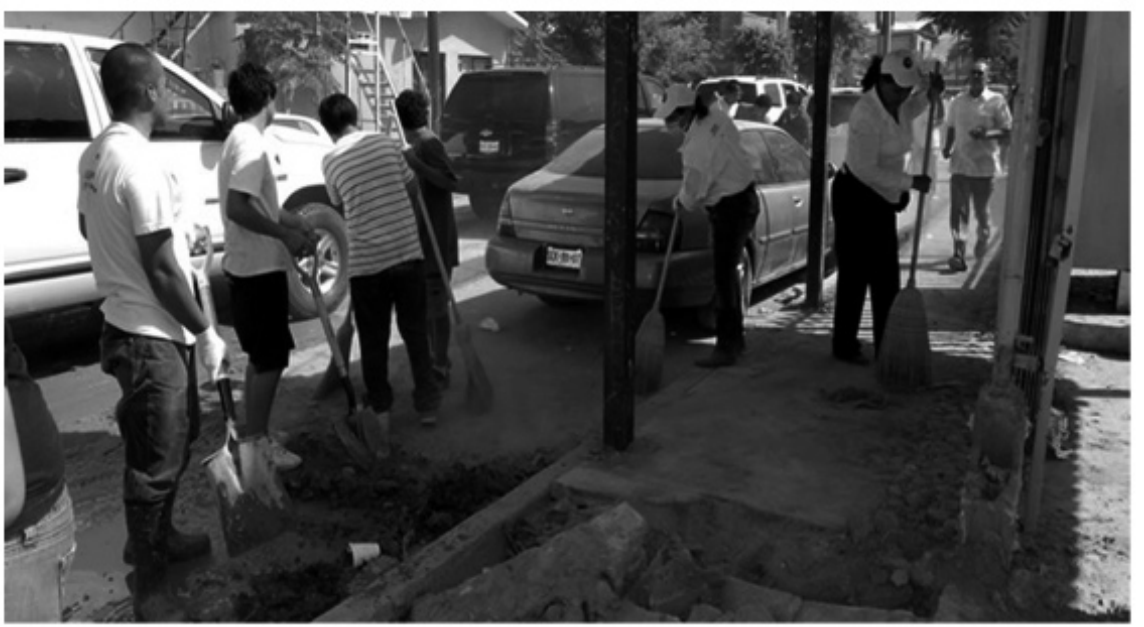

Fuente: SEDESOL, http://www.sedesol.gob.mx/es/SEDESOL/Empleo_Temporal_PET

Una aproximación a la revisión de la operación del PET a nivel nacional sugiere que la población potencial aglomeraría entre $1.5 \mathrm{y}$ 2.0 millones de personas en el periodo 2008 a 2010. La población objetivo agruparía casi 46 mil personas en 2008, 250 mil en 2009, 153 mil en 2010 y cerca de 275 mil en 2011 . O sea la población objetivo se multiplicaría casi 6 veces en el lapso de 4 años. En cambio la población atendida solo se multiplicaría por 2 al pasar de un registro menor a 190 mil personas en 2008 hasta 342 mil en 2011 (Ver tabla 1). 
Tabla 1. Total de población potencial, objetivo y atendida en el PET, 2008-2011

\begin{tabular}{|c|c|c|c|c|c|}
\hline $\begin{array}{c}\text { Tipo de } \\
\text { Población }\end{array}$ & $\begin{array}{l}\text { Unidad de } \\
\text { Medida }\end{array}$ & 2008 & 2009 & 2010 & 2011 \\
\hline P. Potencial & Personas & $\begin{array}{c}\text { Entre 1'512,097 } \\
\text { y,2'038,333 }\end{array}$ & $\begin{array}{l}\text { Idéntica } \\
\text { al } 2008\end{array}$ & $\begin{array}{l}\text { Idéntica } \\
\text { al } 2008\end{array}$ & n.d. \\
\hline P. Objetivo & Personas & $45,9521 /$ & $\begin{array}{c}250,000 \quad 1 / \\
97610 \quad 2 /\end{array}$ & $153,3361 /$ & 274,752 \\
\hline \multirow[t]{2}{*}{ P. Atendida: } & \multirow[t]{2}{*}{ Personas } & $156,716 \quad 2 /$ & $236,1602 /$ & $\begin{array}{c}468,110 \\
300,0002 /\end{array}$ & \multirow[t]{2}{*}{342,122} \\
\hline & & $189,024 \quad 1 /$ & $262446 \quad 1 /$ & $582,044 \quad 1 /$ & \\
\hline $\begin{array}{c}(P . A * 100) / P . \\
\text { O. }\end{array}$ & $\%$ & 341.0 y $411.4 \%$ & $\begin{array}{c}94.5 \mathrm{y} \\
105.0 \%\end{array}$ & $\begin{array}{l}195.6 \text { y } \\
379.6 \%\end{array}$ & $124.50 \%$ \\
\hline
\end{tabular}

Notas: 1/ De acuerdo al EED del 2010-2011. 2/ De acuerdo al Documento diagnóstico del PET. Fuente: toda la información proviene del Informe 4to. Trimestre Sedesol del año correspondiente. La información del 2011 proviene del informe 3er. Trimestre 2011, Sedesol, 2012. Consulta el 29 de agosto de 2012.

Por lo que respecta a la acepción de protección social, el PET formula que la PS refiere a las intervenciones públicas para ayudar a las personas, familias y comunidades vulnerables a manejar el riesgo en dos componentes: el aseguramiento y la asistencia social. En el caso del primer componente, las acciones están dirigidas a proteger a las personas ante posibles pérdidas de ingreso. En el caso del segundo componente, las acciones están orientadas al desarrollo de capital físico y humano (PET, 2010: 18). Según se ha dicho, el PET considera como rubros de atención: mejoramiento de la salud, preservación del patrimonio histórico, mejoramiento de infraestructura local, conservación y reconstrucción de la red rural y alimentaria, la conservación ambiental, la comunicación educativa ciudadana, y el apoyo a jóvenes para la educación y el empleo. Por lo que compete a los tipos de apoyo se consideran los apoyos directos, apoyos para la ejecución de proyectos y los apoyos a la participación social (ver tabla 2). 


\begin{tabular}{|c|c|c|c|}
\hline Tipos de Apoyo & Apoyo & Descripción & Características del Apoyo \\
\hline Apoyos Directos & $\begin{array}{c}\text { Apoyo } \\
\text { económico al } \\
\text { beneficiario }\end{array}$ & $\begin{array}{c}\text { Se otorgará un } \\
\text { apoyo económico, } \\
\text { consistente en jor- } \\
\text { nales equivalentes } \\
\text { al 99\% de un sala- } \\
\text { rio mínimo general } \\
\text { diario vigente en el } \\
\text { área geográfica en } \\
\text { que se desarrolla } \\
\text { el proyecto. }\end{array}$ & $\begin{array}{l}\text { Recursos entregados a los } \\
\text { beneficiarios a través de me- } \\
\text { dios electrónicos, en cheque } \\
\text { o en efectivo hasta por un } \\
\text { máximo de } 2 \text { jornales diarios } \\
\text { y } 132 \text { jornales por ejercicio } \\
\text { fiscal por beneficiario. El mon- } \\
\text { to por jornal puede consultar- } \\
\text { se en la página electrónica } \\
\text { del CIPET www.cipet.gob.mx. }\end{array}$ \\
\hline $\begin{array}{l}\text { Apoyos para } \\
\text { la ejecución } \\
\text { de proyectos }\end{array}$ & $\begin{array}{c}\text { Apoyo para } \\
\text { Adquisición o } \\
\text { Arrendamien- } \\
\text { to de He- } \\
\text { rramientas, } \\
\text { Materiales y } \\
\text { Equipo; así } \\
\text { como costos } \\
\text { de transporte }\end{array}$ & $\begin{array}{l}\text { Se podrán otorgar } \\
\text { apoyos econó- } \\
\text { micos para la } \\
\text { adquisición o } \\
\text { arrendamiento } \\
\text { de materiales, } \\
\text { herramientas, ma- } \\
\text { quinaria o equipo, } \\
\text { así como costos } \\
\text { de transporte } \\
\text { necesarios para } \\
\text { realizar los proyec- } \\
\text { tos autorizados. }\end{array}$ & $\begin{array}{l}\text { El porcentaje máximo del } \\
\text { presupuesto destinado a } \\
\text { este apoyo es del } 30 \% \text {. }\end{array}$ \\
\hline
\end{tabular}




\begin{tabular}{|c|c|c|c|}
\hline $\begin{array}{l}\text { Apoyos a la } \\
\text { participa- } \\
\text { ción social }\end{array}$ & $\begin{array}{l}\text { Acciones de } \\
\text { Promoción } \\
\text { y Participa- } \\
\text { ción Social }\end{array}$ & $\begin{array}{l}\text { Son aquellas orien- } \\
\text { tadas a favorecer } \\
\text { la participación de } \\
\text { los beneficiarios } \\
\text { para el desarrollo } \\
\text { personal, familiar y } \\
\text { comunitario, imple- } \\
\text { mentadas según } \\
\text { los Lineamien- } \\
\text { tos que fijen las } \\
\text { Dependencias en } \\
\text { congruencia con } \\
\text { las particularidades } \\
\text { de cada proyecto. } \\
\text { Adicionalmente, } \\
\text { para el otorgamien- } \\
\text { to de este apoyo } \\
\text { se contempla la } \\
\text { compensación } \\
\text { económica a } \\
\text { Gestores Volunta- } \\
\text { rios y la realización } \\
\text { de acciones de } \\
\text { capacitación para } \\
\text { la conformación } \\
\text { ded Social. }\end{array}$ & $\begin{array}{l}\text { La Red social fomentará la } \\
\text { participación social, mediante } \\
\text { actividades relacionadas con: } \\
\text { • Acciones de prevención y } \\
\text { remediación contra desastres } \\
\text { • Educación para aminorar } \\
\text { los daños provocados por } \\
\text { desastres } \\
\text { - Talleres de planeación y } \\
\text { organización participativa } \\
\text { - Otros temas en beneficio } \\
\text { familiar o comunitario. }\end{array}$ \\
\hline \multicolumn{4}{|c|}{$\begin{array}{l}\text { En el caso de los gastos desglosables del Programa de Emplec } \\
\text { Temporal, el reporte del Primer trimestre } 2011 \text { y el Presupuesto Tota } \\
\text { Ejercido reporta un aproximado a } 806 \text { millones de pesos para gastos } \\
\text { de operación de la SEDESOL }(98.2 \%) \text { y } 1.8 \% \text { (casi } 15 \text { millones de } \\
\text { pesos) para gastos en mantenimiento. En suma, el gasto unitario equi- }\end{array}$} \\
\hline
\end{tabular}


vale a cerca de 3 mil pesos por persona cuya asignación comprendería alrededor de 273 personas atendidas (ver tabla 3).

Tabla 3. Gastos desglosables del PET, 2011

\begin{tabular}{|c|c|c|}
\hline Concepto & \multicolumn{2}{|c|}{ SEDESOL } \\
\hline 1. Gastos en Operación: & $805,951,587.70$ & 98.2 \\
\hline 1.a Gastos Directos & $790,352,810.00$ & 96.3 \\
\hline 1.a.i Gasto por subsidios (Cap. 2000 y 3000) & $779,927,286.00$ & 95 \\
\hline 1.a.ii Gasto en personal (Cap. 1000) & $10,425,524.00$ & 1.3 \\
\hline 1.b Gastos Indirectos (Cap. 2000 y 3000) & $15,598,777.70$ & 1.9 \\
\hline 2. Gastos en Mantenimiento: & $14,968,844.58$ & 1.8 \\
\hline 3. Sub Total & $820,920,432.28$ & 100 \\
\hline 3. Gastos en Capital & n.d. & \\
\hline 4. Gasto Unitario: & 3006.22 & \\
\hline (1. + 2.)/ Población atendida & & \\
\hline Población atendida & 273074 & \\
\hline SEMARNAT 3. Subtotal & $498,480,900.00$ & 100 \\
\hline
\end{tabular}

Fuente: Elaborado en base a SEDESOL, cuadro "Presupuesto total ejercido" y SEMARNAT, "Reporte tercer trimestre 2011, PET". Secretaría de Desarrollo Social, SEDESOL, http://www.sedesol.gob.mx/es/ SEDESOL/

Por lo que respecta a la cobertura del PET en Juárez durante el periodo $2009-2010$ se tiene que aquella incrementó en $45 \%$ en el caso de los atendidos y aumentó un $93.41 \%$ en el caso del grupo de los colocados en el mismo periodo. Pero lamentablemente, la variación porcentual de personas colocadas por el PET en el periodo 2010-2011 fue negativa al descender a $-33.10 \%$ (ver tabla 4). Esta situación se supondría en general optimista al advertir que este grupo de población es beneficiario del PET, en tanto reciben recursos en efectivo o en especie; lo desafortunado de esta lectura es que ser una persona atendida o colocada no significa que se le contrate en programas de empleo permanente, sino que se le auxilia de manera temporal. 
Tabla 4. Cobertura del PET en Juárez, 2009-2010

\begin{tabular}{|c|c|c|c|c|c|c|c|}
\hline Juárez & \multicolumn{2}{|c|}{2009} & \multicolumn{2}{|c|}{2010} & 2011 & Variación \% & Variación \% \\
\hline 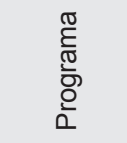 & $\begin{array}{l}00 \\
\frac{0}{0} \\
\frac{0}{0} \\
\frac{c}{0} \\
\frac{D}{<}\end{array}$ & $\begin{array}{l}\text { o } \\
\frac{0}{0} \\
\text { ర } \\
\text { 응 }\end{array}$ & $\begin{array}{l}00 \\
\frac{0}{0} \\
\frac{0}{0} \\
\frac{0}{0} \\
\frac{\Phi}{4}\end{array}$ & 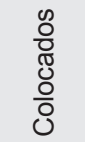 & $\begin{array}{l}\text { O } \\
\frac{0}{0} \\
\text { ரू } \\
\text { 응 }\end{array}$ & 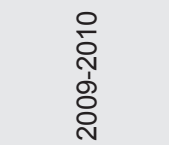 & $\begin{array}{l}\text { 호 } \\
\text { ó } \\
\text { o }\end{array}$ \\
\hline $\begin{array}{c}\text { Programa } \\
\text { Empleo } \\
\text { Temporal }\end{array}$ & 4,891 & 2,535 & 7,092 & 4,903 & 3,280 & 45.0 & -33.10 \\
\hline
\end{tabular}

Fuente: Elaboración propia con base en el Servicio Nacional de Empleo. Información disponible en el sitio http://www.empleo.gob.mx/wb/BANEM/B.

En el caso de las personas beneficiadas cabe matizar que el género y la edad de una u otra es relevante. Como prueba se observa que los beneficiarios por el PET en Juárez en el año ascendió a un total de 2,509 personas de las cuales 806 correspondió a mujeres (32.1\%) y 1,703 a hombres (67.9\%). En el caso de la edad, los grupos más beneficiados oscilaron entre los 15 y los 64 años de edad al comprender alrededor del $98 \%$ de la población beneficiada por el PET (ver tabla 5).

Tabla 5. Beneficiarios del PET en Juárez, 2012.

\begin{tabular}{|c|c|c|c|c|}
\hline Grupo & Beneficiarios & Mujeres & Hombres & $\%$ total \\
\hline Total & 2,509 & 806 & 1703 & 100 \\
\hline 0 a 14 & 1 & 0 & 1 & 0.04 \\
\hline 15 a 29 & 1240 & 430 & 810 & 49.42 \\
\hline 30 a 64 & 1211 & 367 & 844 & 48.27 \\
\hline 65 y más & 57 & 9 & 48 & 2.27 \\
\hline
\end{tabular}

Fuente: Anexo 12 en http://www.sedesol.gob.mx/es/SEDESOL/Evaluaciones_Anuales_2011

La revisión del registro de beneficiarios en los programas sociales de la SEDESOL para Juárez 2012 capta una cantidad aproximada a 
las 155 mil personas (ver tabla 6). De esa cifra, el padrón de beneficiarios solamente contabiliza un total de 394 personas que equivalen a apenas 0.26 puntos porcentuales del total. Es decir, una cifra irrelevante. Por su parte, los programas más exitosos en materia de desarrollo social son el programa Oportunidades, el programa Liconsa y el programa Hábitat, toda vez que el número de beneficiarios captados por estos tres programas representa casi el $87 \%$ del total; el otro 13\% se distribuye en 8 programas restantes.

Tabla 6. Número de beneficiarios en Juárez de los programas sociales de SEDESOL, 2012

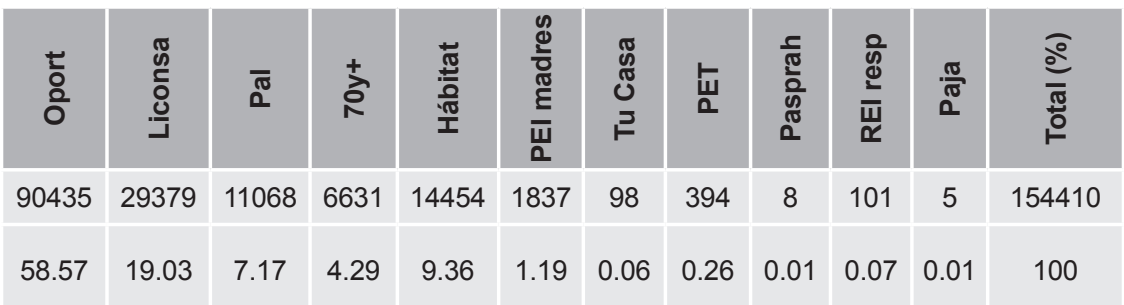

Donde: Oport. Programa de desarrollo humano Oportunidades; Liconsa, Programa de abasto social de leche; PAL, Apoyo alimentario; 70y+, Programa 70 y más; Hábitat, Programa Hábitat; PEI madres, Padres y madres trabajadores del programa estancias infantiles para apoyar a madres trabajadoras; Tu Casa, Programa de ahorro, subsidio y crédito para la vivienda "Tu casa"; PET, Programa de empleo temporal; Pasprah, Programa de apoyo a los avecindados en condiciones de pobreza patrimonial para regularizar asentamientos irregulares; REI resp, Responsables del programa estancias infantiles para apoyar a madres trabajadoras; Paja, programa de atención a jornaleros agrícolas, entre otros.

Fuente: Elaboración propia. http://www.sedesol.gob.mx/es/SEDESOL/Padron_de_beneficiarios

En el caso de la distribución de recursos del PET (ver tabla 7) se tiene que del presupuesto anual destinado (en cifras redondas) 6.5 de cada 10 pesos fueron para el apoyo económico de los beneficiarios; casi 2.8 de cada 10 se destinaron a la adquisición o arrendamiento de herramientas, materiales y equipo, y el resto, casi 0.70 de cada 10 pesos se destinó a las tareas de operación, supervisión, difusión, seguimiento y evaluación externa del programa. 
Tabla 7. Distribución de recursos del PET

\begin{tabular}{|c|c|}
\hline Concepto & Porcentaje \\
\hline Presupuesto anual destinado al apoyo económico de los beneficiarios & $65.27 \%$ \\
\hline $\begin{array}{c}\text { Presupuesto anual máximo destinado a la adquisición o } \\
\text { arrendamiento de herramientas, materiales o equipo }\end{array}$ & $28.00 \%$ \\
\hline $\begin{array}{c}\text { Presupuesto anual destinado a la operación, supervisión, difu- } \\
\text { sión, seguimiento y evaluación externa del programa PET }\end{array}$ & $6.73 \%$ \\
\hline
\end{tabular}

Fuente: Elaboración propia con base en el Servicio Nacional de Empleo. Información disponible en el sitio http://www.empleo.gob.mx/wb/BANEM/B.

En términos globales, la SEDESOL reporta un presupuesto aprobado para el PET — para el año fiscal 2011— de 2,885 millones, pero el presupuesto total asignado con clave 071 fue $\$ 2,875,233,762.00$ pesos; cuya distribución porcentual comprendió $27.4 \%$ para la SEDESOL, $17.3 \%$ para la SEMARNAT y $55.3 \%$ para la SCT. En resumen, el balance general del PET desde su año de inicio de operación - que tuvo lugar en 1997- estima que los beneficiarios de este programa han sido 265,731 personas en 2007; 156,716 en 2008; 236,160 en 2009 y se esperaba llegar a casi 300,000 en 2010. ${ }^{17}$ Esto significa que en Ciudad Juárez, los beneficiarios del PET han sido una cifra insignificante toda vez que este programa no representa ni se aproxima a un $10 \%$ del total nacional ni tampoco ha logrado subsanar el problema de desempleo que aqueja a los residentes de esta localidad. Sin embargo, cabe reconocer que las plazas cubiertas por los solicitantes que fueron colocados han representado una fuente de ingresos para ese reducido grupo de la población. Del mismo modo, la mayoría de ellos ha tenido oportunidad de participar en proyectos o actividades laborales relacionadas con el mejoramiento de la infraestructura local, favoreciendo con ello el estatus de emergencia social que atraviesa esta ciudad.

En definitiva, el diagnóstico realizado del PET conduce a aceptar que este programa emergió en Ciudad Juárez bajo un formato centra-

17 Fuente: http://www.sedesol.gob.mx/es/SEDESOL/Empleo_Temporal_PET. 
lizado, no autónomo, que como política ha intentado hacer frente a las contingencias coyunturales con la expectativa de contribuir a la protección social, cuya dinámica ha sido afectada por la desestabilización económica. En apariencia, el PET sí capta a un número limitado de usuarios que en términos reales solo representa un "abultamiento" en las estadísticas. Así lo muestran las cifras. Por ello, partiendo del hecho de que los beneficiarios del Programa Empleo Temporal solamente pueden hacer uso limitado del recurso otorgado, y considerando que los resultados del impacto social suponen limitaciones para su interpretación, dado su carácter temporal, es pertinente admitir que queda pendiente formular un índice que permita monitorear los resultados del PET, así como sus impactos, de modo que haga posible sugerir evaluaciones y diseños de política pública acordes con los esquemas de protección y política social en beneficio de la población de Ciudad Juárez. De esta forma, una propuesta — sujeta a revisión- de ese índice puede considerar los siguientes componentes evaluación sujeta a cobertura, edad de beneficiarios e ingresos asignados (ver ecuación 1).

$$
\operatorname{IEPETi}, j=\frac{I C B i, j|I E B i, j| I I i, j}{3} ; 0 \leq I \operatorname{EPET} i, j \leq \mathbf{1}
$$

(ecuación 1)

Donde: IEPETi,j es el índice de evaluación del PET en la localidad i en el año j; ICBi,j es el índice de cobertura de beneficiarios del PET en la localidad i en el año j; IEBi,j es el índice de edad de los beneficiarios en la localidad i en el año j; e IIi,j es el índice de ingresos asignados a cada beneficiario en promedio en la localidad i en el año j. Los parámetros de cada índice van de 0 a 1 . Si es 1 , ocurre que el PET sí cumple con su propósito y misión. Así se tiene que si aplicamos el cálculo del IEPETi,j para Juárez en el año 2010, el ICB= número de colocados/número de atendidos es 4903/7902=0.6913; el IEB=beneficiarios por grupo de edad/ total de beneficiarios que equivale a $1240 / 2509=0.4944$ y el II = logaritmo natural del gasto unitario por beneficiario entre 10 sugiere que II es $\ln$ de 3006.22 /10 = 0.8008. 
Por tanto, el IEPET de Juárez en el 2010 equivale a 0.6621, lo que significa que el Programa de Empleo Temporal únicamente está beneficiando al $66 \%$ de la población captada equivaliendo a 2 de cada 3 personas. Este dato no resulta necesariamente erróneo, ya que la evaluación de consistencia y resultados 2011-2012 del PET realizada por el Consejo nacional de evaluación (CONEVAL) reporta que en el 2010, el porcentaje de beneficiarios del programa que percibió una mejoría en sus ingresos y en sus condiciones de vida era del $70 \%$ y $71 \%$, respectivamente. ${ }^{18} \mathrm{O}$ también, el reporte de avances de los indicadores respecto de sus metas publicado por la SEDESOL indica que la medición anual observada para 2011 — por ejemplo - indica que el 70\% de los beneficiarios del PET perciben una mejoría en sus condiciones de vida.

Por lo anterior, cabe no negar que el gobierno mexicano -incluido el gobierno municipal - ha pretendido encaminar las políticas de acción y redistributivas del Programa Empleo Temporal para solventar contingencias de la población más vulnerable sin necesariamente garantizar la competitividad ni la sustentabilidad de este programa ni de otros de desarrollo social en el mediano y largo plazo. En su caso, el PET al igual que Liconsa, Hábitat, Oportunidades o Tu Casa, pueden presumir de ser programas que intentan fungir como un soporte económico en tiempos de crisis social, pero dadas las características y circunstancias sociales de Ciudad Juárez y a sabiendas de que tales programas se implementan con la finalidad de mejorar las condiciones sociales predominantes, se hace necesario que los programas de desarrollo social logren incidir mediante la promoción y distribución equitativa de recursos y satisfactores que alcancen a satisfacer las necesidades cotidianas de la sociedad.

Por estas razones, el cumplimiento de los objetivos de la política social en esta localidad debe estar en función no solamente de la

18 Fuente: Informe final PET.pdf. Evaluación y consistencia de resultados 2011-2012 del PET. SEDESOL. S-071. http://www.coneval.gob.mx/cmsconeval/rw/pages/ evaluacion/evaluaciones/consistencia/evaluaciones_de_Consistencia_y_resultados_2011-2012.es.do 
colocación o la cobertura de las plazas o vacantes que se vayan presentando dentro de la dinámica del programa o bien desde el soporte económico que estas actividades puedan brindar, sino también en una posible medición del fortalecimiento o gestación de ciertos y determinados valores cívicos que mediante los proyectos o actividades laborales implementadas como parte del PET puedan desarrollarse. Por consiguiente, el Programa Empleo Temporal puede y debe hacer un mayor esfuerzo por abarcar la mayor parte de los rubros de atención que este programa maneja, ya que en contextos sociales como el de esta ciudad fronteriza, cuestiones como la salud pública, el fomento de la identidad social a partir de elementos culturales de corte histórico, el apoyo a una gran cantidad de jóvenes que en la actualidad no cuentan con un empleo ni tienen acceso a la educación, los esfuerzos por lograr una cultura de sustentabilidad y respeto al medio ambiente, así como el desarrollo de actividades, talleres o cursos que fomenten la cultura cívica en la ciudad, son determinantes y aspectos fundamentales que den cabida a la búsqueda de la tan citada recomposición del tejido social, es decir, de la reestructuración social, política y económica en la vida comunitaria de Ciudad Juárez. La invitación es que estemos atentos y atentas al transcurso de los acontecimientos.

\section{Conclusiones}

El crecimiento de las filas o tasas de desempleo se ha convertido en la década reciente en un problema de tal magnitud que, de no tomarse las medidas necesarias, puede traducirse en un problema de salud pública. Tan necesario resulta atender esta problemática que la instrumentación de la protección social a favor de los trabajadores requiere soportarse en una plataforma de políticas del ámbito laboral, productivo, económico, demográfico, social y asistencial, a partir de las cuales sea posible superar las situaciones de riesgo para el conjunto de la población sin afectar particularmente a los hogares marginados y/o más pobres.

Sin lugar a dudas, las políticas eficaces para corregir la pobreza, la desigualdad y la falta de oportunidades son una necesidad apremiante 
en la comunidad mexicana. La redistribución de la riqueza, la protección, la cohesión y la justicia social deben considerarse como una parte medular en el diseño de las políticas públicas, ya que no solo proporcionan un conjunto de instrumentos para regular y complementar las instituciones del mercado y las estructuras sociales, sino que aseguran que el radio de influencia de la protección social tienda a ser no limitada. Según puede observarse en los hallazgos de este trabajo, la protección social y su relación con el ámbito laboral representan un desafío para México y de manera particular para Juárez. Por ende, es necesario reformular la política social en aras de conseguir un mayor impacto a largo plazo para beneficio de los sectores más vulnerables del país.

La protección social puede aceptarse como un instrumento útil para la promoción del bienestar humano que favorece la integración y equidad de hombres y mujeres en situación de vulnerabilidad. En el caso de la protección social, los programas de emergencia vinculados específicamente con el empleo temporal deben operar bajo mecanismos eficaces que respondan a situaciones de crisis para aportar ingresos a los grupos de población más vulnerable. En estas condiciones, las experiencias caóticas en materia de desempleo ocurridas en Juárez implicaron como alternativa de protección social el Programa de Empleo Temporal en el marco de la estrategia Todos somos Juárez. En síntesis, el PET es un programa necesario, pero no suficiente para superar los problemas de empleo, seguridad y crisis que se padecen en la ciudad. La dificultad más importante del PET consiste en su baja cobertura no solo en términos de cantidad de beneficiarios, sino en los esquemas de calidad o prestaciones otorgadas. Los resultados del impacto social de este programa desde la postura de la política social suponen limitaciones para su interpretación; si partimos del hecho de que los beneficiarios solamente pueden hacer uso limitado de este recurso y de manera temporal, sucede que no cabe la posibilidad de preservar de manera permanente el empleo y mucho menos prestaciones adecuadas. Por tanto, pese a que los informes de este programa indiquen que capta a un gran número de usuarios - que solo terminan inflando las estadísticas - resulta que los beneficios son temporales y 
limitados. Así mismo, otra limitación del programa surge cuando estipula que para ser beneficiario del PET debe ocurrir que incluye a personas afectadas por la baja oferta laboral o a agentes vulnerables que para acceder a apoyos económicos deben garantizar su participación en proyectos comunitarios o los establecidos en el programa. Por tanto, vale sugerir que cada programa que opere bajo un esquema de protección social ha de tener como objetivo aplicarse de manera permanente, de modo que permita no solo elevar las capacidades de los individuos y sus familias para cubrir sus necesidades básicas, sino lograr la coordinación de tareas diversas que permitan tanto la asignación eficiente de los recursos públicos como el fomento a la participación ciudadana.

\section{Referencias}

Agencia informativa latinoamericana. Masiel Fernández Bolaños en http://www.prensa-latina.cu/index.php?option=com_content\&tas k=view\&id=539991\&Itemid=1. Consulta el 30 de agosto de 2012. Banco Interamericano de Desarrollo. (2000). Protección social para la equidad y el crecimiento. Washington, D.C.: Inter-American Development Bank.

Barraza, Laurencio. (2009). Diagnóstico sobre la realidad social, económica y cultural de los entornos locales para el diseño de intervenciones en materia de prevención y erradicación de la violencia en la región norte: El caso de Ciudad Juárez, Chihuahua. México. Recuperado el 28 de noviembre de $2011 \mathrm{en:} \mathrm{http://bit.ly/sDIQEF.}$

Ceja, Concepción (2004). "La política social mexicana de cara a la pobreza", en: Revista electrónica de Geografía y Ciencias Sociales Script Nova, noviembre de 2004, vol. VII, núm. 176. Universidad de Barcelona (en línea). Disponible en http://www.ub.edu/geocrit/ sn/sn-176.htm.

Comisión Económica para América Latina y el Caribe. (2011). La protección social de cara al futuro: acceso, financiamiento y solidaridad. Recuperado el 25 de marzo de 2011 en: http://bit.ly/rQL1V7

El Financiero. "Empleo, pobreza y hambre". Miércoles, 22 de agosto de 2012.Redactor:MargaritaVegaenhttp://www.elfinanciero.com.mx/ 
index.php?option $=$ com_k2\&view $=$ item $\&$ id $=36127 \&$ Itemid $=26$ Consulta el 23 de julio de 2012

El Financiero. Rosalinda Velez Juárez, secretaria del Trabajo y Previsión Social. Cuartoscuro. Edgar Amigón/Finsat. Empleo, Pobreza y Hambre.Lunes, 23 de julio de 2012.11:32.Redactor:Miriam Castro en http://www.elfinanciero.com.mx/index.php?option=com_k2\& view=item\&id=31426:\&Itemid=26. Consulta el 23 de agosto de 2012.

El Universal. Luis Carlos Cano C. "El número de despidos este año es menor al de 2001, afirman representantes de las plantas maquiladoras y la Cámara Nacional de la Industria de Transformación”. Jueves 02 de mayo de 2002 en http://www2.eluniversal.com.mx/pls/ impreso/noticia.html?id_nota $=454438$ tabla=estados. Consulta el 19 de julio de 2012

---http://www2.eluniversal.com.mx/pls/impreso/noticia.html?id_ nota $=45443 \&$ tabla $=$ estados. Consulta el 19 de julio de 2012 .

Instituto Nacional de Estadística y Geografía (2012). XIII Censo de Población y Vivienda .Aguascalientes. http://www.inegi.org.mx/

Mexico Solidarity Network, Red de solidaridad con México en http://www.mexicosolidarity.org/post/2011/september/ desempleoenciudadju\%C3\%A1rez. Consulta el 19 de agosto de 2012.

Montoro, Ricardo (1997). Capítulo 2, Fundamentos Teóricos de la Política Social. Texto disponible en el sitio http://www. uam.es/personal_pdi/economicas/rmontoro/Mis\%20articulos/ politicasocial.pdf

Morales Ramírez, María Ascensión. (2006). "Protección social ¿un concepto dinámico?" Revista Latinoamericana de Derecho Social: Instituto de Investigaciones Jurídicas. Recuperado el 7 de Abril de 2011 en: http://bit.ly/vGBI3z

Organización Internacional delTrabajo,OIT(2012) en http://www.oit. org.pe/index.php?option=com_content\&view=article\&id=2528:casi-7-millones-de-jovenes-estan-desempleados-y-unos-27millones-estan-confinados-a-la-informalidad-en-america-latina- 
y-el-caribe\&catid=117:ultimas-noticias\&Itemid $=1305$. Consulta el 10 de agosto de 2012.

Organización Internacional del Trabajo, OIT (2012). Nota Casi 7 millones de jóvenes están desempleados y unos 27 millones están confinados a la informalidad en América Latina y el Caribe. Viernes, 10 de Agosto de 2012. LIMA enhttp://www.oit.org.pe/index. php?option $=$ com_content\&view $=$ article $\&$ id $=2528$ : - casi -7 millones-de-jovenes-estan-desempleados-y-unos-27-millonesestan-confinados-a-la-informalidad-en-america-latina-y-elcaribe\&catid=117:ultimas-noticias\&Itemid=1305. Consulta el 10 de agosto de 2012.

Ortiz, Isabel (2007). Estrategias nacionales de desarrollo Guías de orientación de Políticas Públicas. New York: Organización de Naciones Unidas, Departamento de asuntos Económicos y Sociales. Recuperado el 18 de noviembre de 2011 en: http://bit.ly/vknsQD Plan Nacional de Desarrollo 2007-2012, PND. Presidencia de la República. México (en línea). Disponible en http://pnd.calderon. presidencia.gob.mx/index.php?page $=$ documentos-pdf

Presidencia de la República.Sitio http://presidencia.gob.mx/.Consulta el 09 de agosto de 2012.

Programa de Empleo Temporal, PET (2010). SEDESOL. Obtenido el 17 de Marzo de 2012 en http://bit.ly/xIeXAe

Saavedra, Raúl (1968). Política social: un marco de referencia. Universidad de Chile. Chile.

Salazar y Valdrini (1988). Análisis del concepto política social. Universidad de Valencia. España.

Salcedo, Diego (2004): Las políticas de empleo y apoyo a las Pymes Industriales en la Provincia de Mendoza. Beca de Iniciación CIUNC Segundo Año, Mendoza.

Samuelson y Nordhaus (1995). Economía. Décimo tercera edición. Mc Graw Hill. México.

Santibáñez Romellón, Jorge. (Coord.). (2007). Trabajo Temporal y Migración Internacional a partir de la experiencia México-Canadá. México: El Colegio de la Frontera Norte, Miguel Ángel Porrúa. 
Secretaría de Desarrollo Social, SEDESOL en http://www.sedesol. gob.mx/es/SEDESOL/Empleo_Temporal_PET. Consulta el 11 y 29 de agosto de 2012.

Secretaría de Desarrollo Social, SEDESOL, http://www.sedesol.gob. $\mathrm{mx} / \mathrm{es} / \mathrm{SEDESOL} /$

Secretaría de Desarrollo Social. SEDESOL (2012). Informe final PET.pdf. Evaluación y consistencia de resultados 2011-2012 del PET.SEDESOL.S-071.http://www.coneval.gob.mx/cmsconeval/ $\mathrm{rw} /$ pages/evaluacion/evaluaciones/consistencia/evaluaciones_de_ Consistencia_y_resultados_2011-2012.es.do

Servicio Nacional de Empleo. Información disponible en el sitio http://www.empleo.gob.mx/wb/BANEM/B.

Sottoli, (2002) La política social mexicana de cara a la pobreza, cuya descarga gratuita está disponible en el sitio http://www.ub.edu/ geocrit/sn/sn-176.htm. Además ver referencia bibliográfica en este artículo

Velázquez, Héctor. Profesor de Economía. Entrevista de Héctor Moctezuma,columnista de Milenio EdoMex.Video del 16 de agosto de 2010. Ver http://www.youtube.com/watch?v=AoWlHnc8dY0. 